\title{
IMAGE: ITS POWER, USE, AND ABUSE
}

\author{
SHARAF REHMAN
}

\begin{abstract}
This position paper addresses three areas in which photographic images are used and abused: Journalism, Advertising, and Public Relations. These areas do not use images for aesthetic purposes only; for these businesses, the images are more than mental impressions. In these three industries, the messages they deliver through the images have little to do with the objective reality. All three use images to deliver an opinion in the name of journalism, distorted needs, benefits, and solutions in advertising, and put spins on facts to present favorable images of their clients in Public Relations. Historically, all three have engaged in the unethical use of the concept "image making" and of manipulation of actual images.
\end{abstract}

Key words: image manipulation, ethics, photojournalism, public opinion, alternative news

\section{Introduction}

Today, photography is more popular than it has ever been. Smartphones and digital cameras have empowered people globally. In all remote corners of the planet, people of all ages are creating, sharing, and manipulating images. In some ways, the digital technology has democratized the mankind in an unprecedented manner. The number of digital cameras sold annually is in millions; $98.4 \%$ of the consumer cameras sold in 2016 were built into the smartphones, $0.8 \%$ were compact cameras, only $0.5 \%$ were DSLRs (Zhang, 2017). The numbers of pictures created and shared on the Internet are in billions. The fascination with images translates into huge profits for the manufacturers of digital devices, and the social media outlets such as YouTube, Facebook, and Instagram. Humanity's fascination with images, however, is nothing new. From the pre-historic cave drawings to the digital images, from the flickering silent moving pictures of the 1890s to the 3-D television images, mankind has enthusiastically embraced every imaging innovation. Today, for most people, a world without pictures would be unimaginable. 
Some documentary photographers such as Dorothea Lange, and Shelby Lee Adams have used images to inform through photojournalism (London and Stone, 2012), others have found medical applications in electron microscopy, and in exploration of space. Advertisers have used images to persuade and influence buying behavior, and the public relations professionals have used photographs to repair damaged images of their clients. Generally, almost all photographs require some minor adjustments such as cropping, contrast adjustment, brightening the dark areas, and darkening the areas that may be too bright. Colors may also need some adjustment. In the days of conventional (wet) photography, these adjustments were made either with the help of filters and selection of particular film stocks, or, in the darkroom while developing the negative or making the prints. It was not unusual for portrait photographers to retouch and remove any blemishes or soften the marks of aging on the photographs of their clients (Lester 1991; Kobre, 1995). No one considered 'retouching' as unethical (Slater, 1995). Nor did the movie audience object to techniques such as rear-projection or double exposure. These were accepted devices to move the narratives forward. In the realm of creative work, and in the makebelieve world of cinema, the use of table-top photography, stunt artists, doubles, and make up are readily accepted by the viewers. No one would argue that using 'doubles' or stand-ins in the movies is unethical.
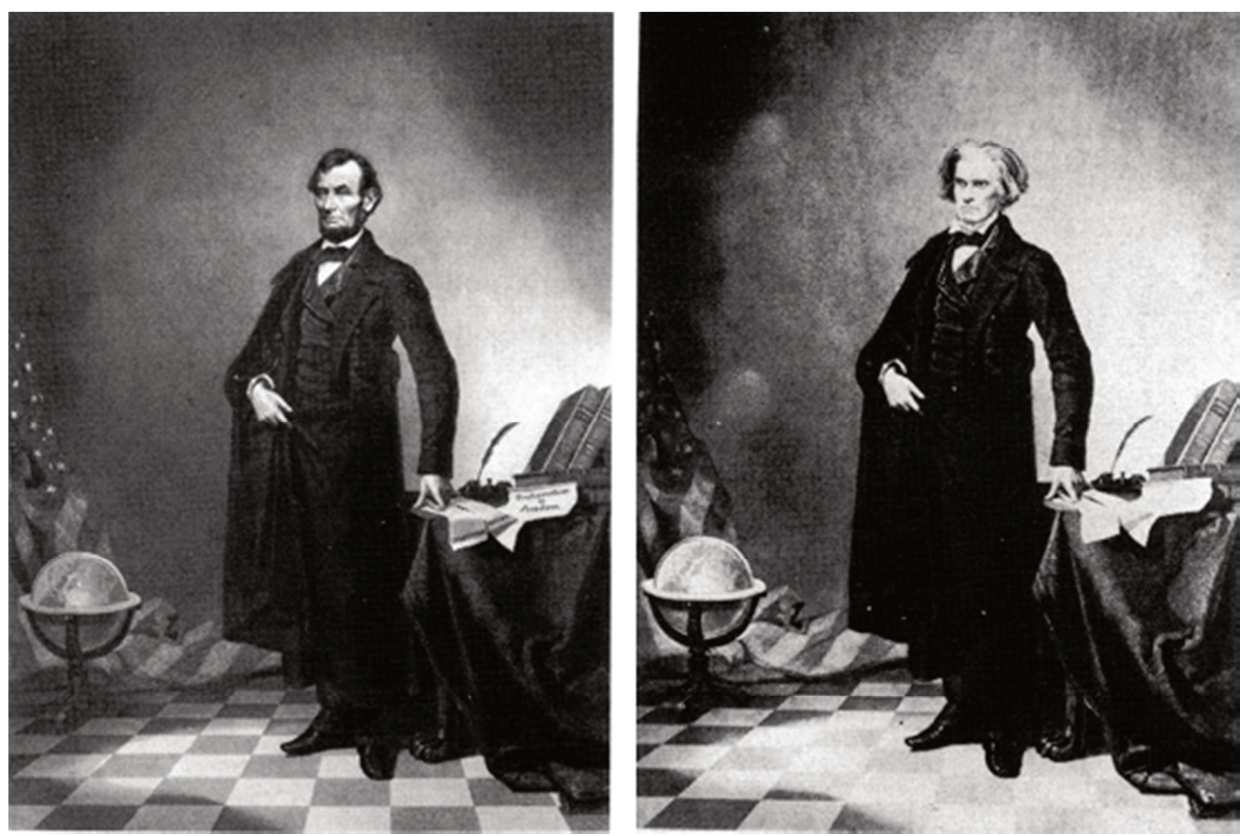

Picture no 1.

(source: http://pth.izitru.com/1860_13_00.html) 
Manipulation of images did not begin with fashion photography or cinema. Nor did it end there. Doctoring of pictures that were intended as historical records and were supposed to represent the facts has a long history of image manipulation. For instance, the famous portrait of Abraham Lincoln by Mathew Brady was a composite of two pictures: the face of Abraham Lincoln and the body of John Calhoun (see Picture no 1).

More recently, TV Guide magazine published a picture of Opera Winfrey with the body of Ann-Margret (see Picture no 2).

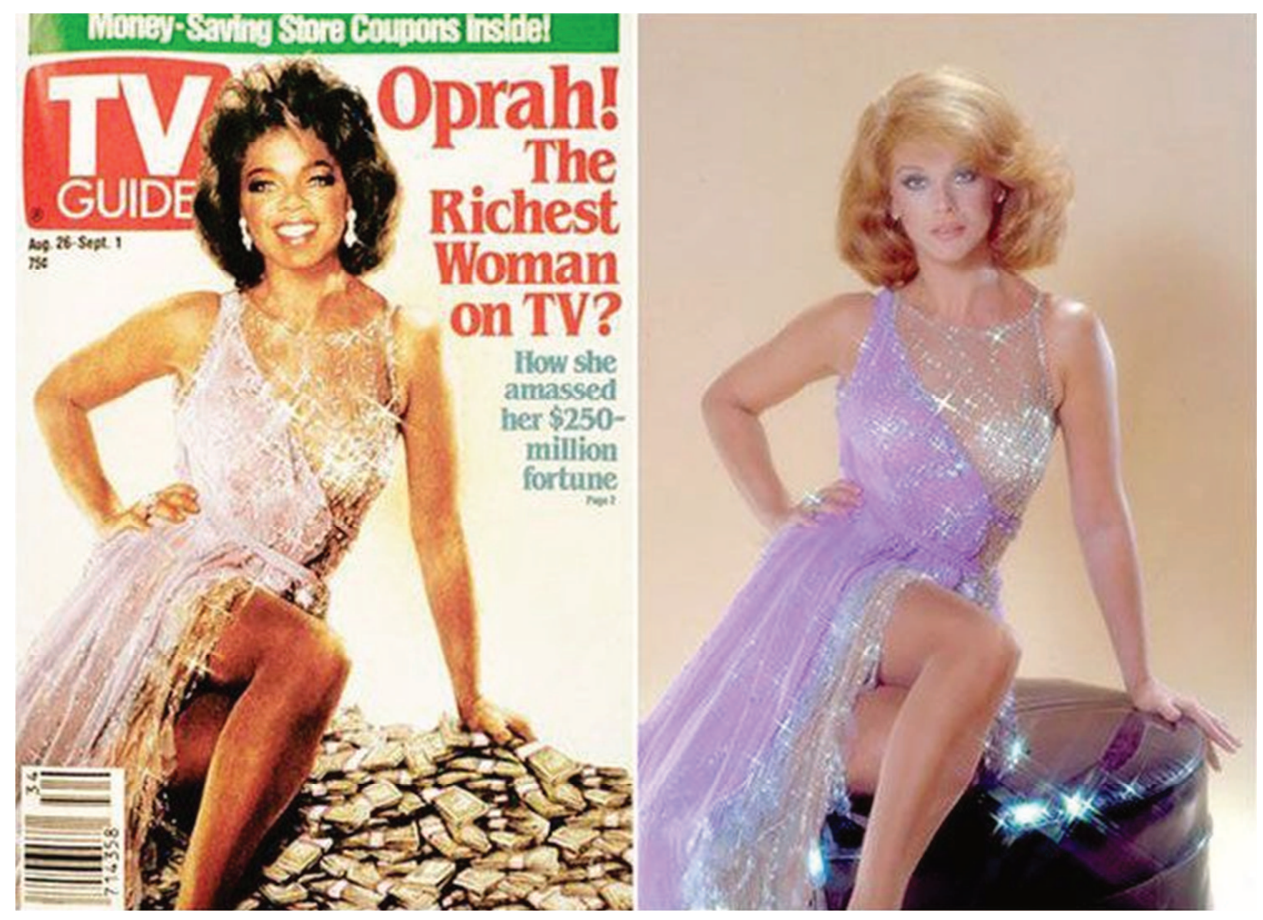

Picture no 2.

(source: https://www.theatlantic.com/technology/archive/2012/06/oprahs-head-ann-margarets-body-a-brief-history-ofpre-photoshop-fakery/258369/)

Images of the Civil War were arranged (staged) to achieve certain emotional impact (Farid, 2009:Mindle, 2016), the raising of the American flag at Iwo Jima by Joe Rosenthal was not a spontaneous shot. Rosenthal took several pictures along with Sergeant Genaust who was recording the stage event with a motion picture camera. By any journalistic standard, the actions of Brady and Rosenthal would be considered unethical. 


\section{Ethics and morals}

The Greek word, éthikos means 'of, or, for morals'. It's for this philological connection that many use ethics and morals interchangeably. However, morals and ethics are not the same.

Morals carry a religious connotation with an idea of external control. Morals are concerned with good and evil, however, these don't have to be rational. Morals create a sense of obligation. Ethics deals with reasoning and rationale for human conduct. The goal is to seek secular objectivity. It suggests a control from within. It is not authoritarian and does not dictate certain behaviors. It creates a sense of responsibility, not obligation.

Most people engage in ethnocentrism - a belief that one's own values, religion, customs, language, and traditions are superior to other culture. I suspect that most people also engage in ethics-centrism. - A belief that one's own moral values or ethical principles are superior to those of the others. A discussion of ethics is the proverbial Pandora's Box.

Yet, ethics is inescapable.

Imagine a society without any codes of conduct. Where people may do absolutely what they please. No rules, no laws, no morals, and no social responsibility. The historians will remind us that the demise of great civilizations and empires occurred due to their decaying of morals and ethical standards. Those nations didn't fail; their institutions collapsed as people abandoned ethics and morals.

\section{The news media}

If we were to discard the unethical or biased behavior of the news media, we would have to disregard the reporting from the newspapers' era of the 'yellow journalism'. We would also have to exclude the tabloids warning us of new sightings of UFOs or two-headed virgins. Using impartiality as a criterion, we would also wonder about the opinion channels such as Fox News and MSNBC, and shock artists such as Rush Limbaugh and Howard Sterns. If we shave off everything that claims to be a news outlet but isn't, we may not have much left. That, in itself, is a sad commentary on today's journalism.

Journalists and the news media, if they report the news, if they keep us informed they don't have to be polite or nice. We accept the news images that are uncomfortable, upsetting, and disturbing. We grant our press a free rein if they deliver on two accounts. 1. Give us a complete version of the truth accessible at the time of the reporting and, 2 do it without bias. Sadly, the record on both accounts is less than satisfactory. There are two key reasons why the news media fall short: objectivity, and the desire to strengthen one's argument by enhancement of images. 
Reporters and journalists, like the rest of us, are guided by their values and convictions. Through these yardsticks, we measure right and wrong, good and bad, and just and unjust. Our objectivity is colored by our moral/ethical codes. Despite our effort to remain impartial, our own ethical standards make us view an event in a certain light.

Most journalists would agree that it's impossible to remain detached from a story. The referees in a football match make the calls as they see them, from their position and perspective. Do the umpires and referees make errors? Of course, they do. With the aid of multiple cameras and action replays, sometimes it's possible to correct a call. News events do not always unfold in front of multiple cameras. The reporting of an event is one person's impression of the truth. The race against time for meeting the deadlines, and beating the competition leaves little time for fact-checking, contacting the credible sources, and gathering all sides of a story. According to a Gallup report, the credibility of the news media hit its lowest in 2004 and hasn't recovered since. The media coverage of the politicians and the campaigns for the 2016 Presidential campaign has all but shattered the image of the new media as a credible institution.

When it comes to the actual images and news, the photographers and photojournalists have historically been less than honest. The American photographer, Mathew Brady, who "documented" the Civil War, arranged his war pictures; Robert Capa, another celebrated, war photographer also staged his pictures.

Even if a picture isn't digitally cropped or enhanced, the composition of a photograph, i.e., what is included, and what is left out, is a subjective choice by the photographer. So is the arrangement of elements within a frame. The objects placed in the foreground become more important than the ones in the background. The objects closer to the middle of the frame dictate more attention than the objects in the in the corners. Additionally, the angle of the camera, the type of lens, filters, and the levels of contrast can all be used to manipulate the emotional impact, perspective, tone, and overall impression of a photographic image. It is naïve to thank that a camera produces objective reality or that a camera never lies. It would be more accurate to say that a camera has seldom told the whole truth.

Journalism and the news media have the power to create and reinforce positive or negative images of individuals, of a people, of places, of nations, and of ideologies. The record shows that the journalists have not refrained from abusing this power. Instead of helping us understand the world around us, the journalists have created divisions through their unethical use of language and images.

\section{Advertising}

The advertising industry, although claims to be in the communication business, is really in the business of image manipulation through giving half-truths, making misleading claims, and using altered images of the results rendered by various product and services. 
If we try to imagine the concept of honest advertising, we may have to search all corners of our memory to come up with an example of an honest-to-goodness advertisement. Deception and false claims are not new to advertising. The early ads for "miracle drugs" that cured everything from common colds to tuberculosis, and bronchitis to weight loss, in reality, were nothing but syrups containing more than fifty percent alcohol, and cured nothing. However, during the nineteenth century, advertising was not a big business and the levels of deception, misinformation, and corruption associated with advertising were relatively small.

In 2018, it is a multi-billion-dollar industry, giving us suggestions and ideas on how we should look and what an ideal body is, what perfect hair is supposed to be, and what our nails, skin, and eyes should look like. The images of perfect bodies, flawless skins, and shiny hair are created through image manipulation. It's easy to see that the ads for food, drugs, dietary supplements, cosmetics, clothing, tobacco, and alcohol are intended to create a sense of insecurity and inadequacy among the consumers; the advertised products are the cure for our shortcomings.

Fully aware that the fast food and carbonated soft drinks are bad for consumers of all ages, that the chemicals in the processed foods and the cosmetic products are harmful, that smoking has been proven to be hazardous to one's health, the manufacturers of these and many other products continue to engage in deceptive advertising, and making empty promises through double-speak, and vague language. Where ever the tobacco and alcohol industries can advertise, they continue to place their ads near the schools and in supermarkets to cultivate an awareness and interest among the children and young adults. Tobacco and alcohol industries, through product placement in the movies and television programs, continue to romanticize and glamorize smoking and drinking.

There are no sacred images in advertising. From Mosses and Mary to the Pope, and from images of starving children to other human sufferings, anything and everything may be used to sell a product. From God and religion to human body, and bodily functions, everything is fair game in advertising. Thanks to television, early pregnancy tests, erectile dysfunction, hemorrhoids, vaginal rinses, and digestive difficulties are a routine part of evening programming.

The advertising industry treats the real people in an unrealistic way. It treats the consumers as 12 -year olds. The language, the visuals, and the overall stance of many of the ads are as if they are aimed at an imbecile. Not only is most advertising offensive, it is impertinent. The messages that are yelled at us in the ads, if someone whispered to us in real life, we may want to slap their face. Would we permit another person to tell us that we are idiots for not using a certain shampoo, or that we chose the wrong insurance company, or that we carry a wrong credit card, or that our feet smell, or we have body odor? Advertising does exactly that - blatantly and repeatedly. 


\section{The public relations}

While advertising cultivates, and repairs the image of a product, public relations professionals work on creating and repairing the images of companies, corporations, and individuals. It is understood that corporations are driven by profit maximization, and as such, their approach is reactive rather than proactive. Instead of doing the right thing in the first place, they call upon the PR folks after something goes wrong.

Corporations waited until after the tragedies such as the Union Carbide in India, Valdez oil spill, the BP spill in the Mexican gulf. Multinational such as the VW group continued to act unethically until they were caught s cheating with emission controls. Wells Fargo bank relentlessly defrauded its customers by opening accounts without their permission and charged late fees on bills that were purposefully sent close to due dates. Honda has been fined millions of dollars for underreporting the fatal accidents involving Honda vehicles. Takata, knowingly, sold faulty airbags to automakers around the world. The company has gone bankrupt and gone out of business. More than 42 million automobiles sold in the U.S. have to be recalled and refitted with replacement airbags. Public Relation's work has become synonymous with polishing the tainted image. Reporters and journalists are called paparazzi or the ambulance chaser, the advertising people are referred to as hucksters, and the PR professional are known as the spin doctors. These are hardly the desirable labels for respectable professions.

\section{Conclusions}

The reason why so many of the practitioners in these three professions misbehave is not because these are ill-meaning individuals. The real reason is that a large percentage of people practicing as reporters, journalists, news photographers, advertising copywriters, and PR professionals lack the formal training in ethics, and journalism. These three professions evolved outside the academe. Journalism has been taught as a university subject for less than 100 years old while the newspapers have been around since 1690 (Hanson, 2017). Courses in newswriting and reporting began as elective courses in the English departments. Many of our famous and respected reporters and journalists of the past and present had no formal journalism training, but acquired knowledge on the job, starting out as copyboys or copygirls.

Even today, in many parts of the world, people start their careers in journalism without any university-level training in research skills, interviewing technique, and academic studies in media, culture, or ethics. Mass media as a discipline is a grandchild of sociology; advertising and public relations still infants academic disciplines are placed either in communication schools of housed within the business programs. Consequently, many of the professionals lack the training in ethics and reasoning, 
persuasion, and objective research. These are the three areas the university curricula stress. It is the lack of these three elements - ethics, reasoning, and objectivity that are missing in the self-proclaimed reporters, advertisers and PR persons.

The universities need to work closely with the three industries and assume a more active role in training the students as responsible journalists and information providers by furnishing them with the tools for rational thinking, logic, ethics, and objectivity in writing and reporting. For if the universities fail to do this, their own role as cultivators of young minds may be at risk.

\section{References}

Farid, H. 2009. "Seeing is not believing". IEEE Spectrum. August. 42-47.

Hanson. R.E. 2017. Mass communication ( $6^{\text {th }}$ ed.). Thousand Oaks, CA: Sage Publications.

Kobre, K. 1995. "The long tradition of doctoring photos". Visual Communication Quarterly 2. 14-15.

Lester, P. 1991. Photojournalism: an ethical approach. Hillside, NJ: Lawrence Erlbaum Associates.

London, B. and Stone, J. 2012. A short course in photography ( $8^{\text {th }}$ ed.). Boston: Prentice Hall.

Mindel, D. 2016. "Approaches and considerations regarding image manipulation in digital collections". IFLA Journal 42, 3. 179-188.

Slater, D. 1995. "Photography and modern vision: the spectacle of "natural magic". In: Jenks, C. (ed.). Visual culture. London: Routledge.

Zhang, M. 2017. "This latest camera sales chart shows the compact camera near death." Petapixel.com. 3 March, 2017. Available from: https://petapixel.com/2017/03/03/latest-camera-sales-chart-revealsdeath-compact-camera/ 